\title{
AVALIAÇÃO DE FATORES DO AMBIENTE DE TRABALHO EM ATIVIDADES DE UM VIVEIRO FLORESTAL DE CURVELO, MINAS GERAIS
}

\author{
Tiago Reis Dutra ${ }^{1}$, Angelo Márcio Pinto Leite², Marília Dutra Massad ${ }^{3}$ \\ ${ }^{1}$ Eng. Florestal, M.Sc., IFNMG, Salinas, MG, Brasil - tiagoreisdutra@ gmail.com \\ 2Eng. Florestal, Dr., UFVJM, Diamantina, MG, Brasil - ampleite@ig.com.br \\ ²Eng롤 Agrônoma, M.Sc., IFNMG, Salinas, MG, Brasil - mariliamassad@ yahoo.com.br \\ Recebido para publicação: 22/09/2010 - Aceito para publicação: 17/12/2011
}

\begin{abstract}
Resumo
O objetivo deste trabalho foi caracterizar e avaliar os fatores do ambiente de trabalho em atividades de um viveiro de propagação de mudas clonais de Eucalyptus spp., visando à melhoria da saúde, do bem-estar, da segurança, do conforto e da produtividade dos trabalhadores envolvidos nessa atividade. A caracterização dos fatores do ambiente de trabalho - sensações térmicas (temperatura, umidade e velocidade do vento), ruído e luminosidade - foram obtidos através da observação direta da unidade de trabalho e aferição de agentes físicos, sendo avaliados os setores de lavagem e desinfecção de tubetes e bandejas, embandejamento e enchimento de tubetes, preparo de substrato, jardim clonal, estaqueamento, casa de vegetação, casa de sombra e crescimento a céu aberto. Das atividades avaliadas, as que se apresentam em níveis inadequados, com limites acima do permitido, correspondem a casa de vegetação (temperatura e umidade), jardim clonal e crescimento a céu aberto (luminosidade), preparo de substrato e enchimento de tubetes (ruído) e velocidade do vento (atividades a céu aberto).

Palavras-chave: Ergonomia; condições de trabalho; produção de mudas.
\end{abstract}

\begin{abstract}
Evaluation of work environment factors in a forest nursery activities from Curvelo, Minas Gerais. The objective of this study is to characterize and evaluate factors of work environment in a nursery for clonal propagation of Eucalyptus spp., in order to improve health, welfare, safety, comfort and productivity of the workers involved in such activity. Factors characterized in work environment: thermal sensations (temperature, humidity and wind speed), noise and light were obtained by direct observation of the work unit and measurement of physical agents, it was evaluated sectors of cleaning and disinfection of tubes and trays, tubes and filling boxing, substrate preparation, clonal garden, staking, greenhouse, shade and growth in the open. Evaluated activities that present inadequate levels, surpassing the allowed limits are as follows: the greenhouse (temperature and humidity); garden and clonal growth in the open (light) substrate preparation and filling of tubes (noise) and speed wind (open activities).

Keywords: Ergonomics; working conditions; production of seedlings.
\end{abstract}

\section{INTRODUÇÃO}

As transformações que se processam no mundo do trabalho atual evidenciam um novo paradigma de organização das relações com o ser humano, que se apoiam, fundamentalmente, na conjugação de abertura de mercados e no desenvolvimento acelerado da tecnologia (ABRAHÃO; PINHO, 2002). Para contornar as condições inadequadas de trabalho criadas ou, em muitos casos, impostas por esse novo processo evolutivo, os estudos ergonômicos atuam como possíveis saídas para se promover melhorias nos ambientes de trabalho de acordo com as características físicas e psicológicas do trabalhador (SILVA et al., 2002).

A aplicação da ergonomia no trabalho é de fundamental importância para assegurar um maior rendimento e um melhor aproveitamento e qualidade das operações, conciliados, principalmente, com a 
saúde do trabalhador, tendo sempre como princípio a adequação do trabalho ao trabalhador (ALVES, 2004).

Os fatores ambientais envolvidos nas atividades dos trabalhadores são importantes variáveis a serem consideradas em uma análise ergonômica de um posto de trabalho. Segundo Fiedler et al. (2006), um local de trabalho deve ser sadio e agradável, além de proporcionar o melhor relacionamento entre a empresa e o empregado, pois, quando desfavoráveis, eles podem provocar exaustão, extenuação física e nervosa, diminuindo o rendimento e a qualidade do trabalho, aumentando, consequentemente, os erros e riscos de acidentes.

Em análises ergonômicas em que se considera o meio físico no qual se efetua um trabalho, as sensações térmicas (temperatura, umidade e velocidade do vento), luminosidade e ruído são fatores ambientais que, quando excedem certos limites, podem provocar doenças ou trazer desconfortos ao bemestar dos trabalhadores.

Situações envolvendo esses fatores são comuns nas atividades de um viveiro de propagação vegetativa de plantas, merecendo estudos para quantificar seus níveis, com o intuito de promover melhorias nesse ambiente de trabalho (ALVES et al., 2002).

A busca constante pela produção de mudas de qualidade com a racionalização de custos de produção, visando fomentar as necessidades das indústrias de base florestal, tem promovido uma maior e constante demanda pelo desenvolvimento tecnológico.

Atualmente, com a maior competitividade do setor florestal, as atividades de produção de mudas são realizadas, na maioria das vezes, visando à maximização dos lucros, à redução dos custos e à otimização da produção, e, nesse contexto, em muitos casos as empresas deixam de investir adequadamente no seu principal recurso/componente de trabalho/produção: o trabalhador (FIEDLER $e t$ al., 2007).

Nesse sentido, os estudos ergonômicos envolvendo o conhecimento das condições do ambiente de trabalho, aliados à saúde e à segurança dos trabalhadores, devem ser observados, para que se torne possível a maximização qualitativa da capacidade de trabalho dos mesmos e, consequentemente, se alcancem as metas/objetivos de produção pretendidos.

Diante do exposto, este trabalho teve como objetivo caracterizar e avaliar os fatores do ambiente de trabalho em atividades de um viveiro de propagação de mudas clonais de Eucalyptus spp. Nesse contexto, a hipótese apresentada para o presente estudo é de que um bom ambiente laboral refletirá em melhorias da saúde, do bem-estar, da segurança e da produtividade das pessoas envolvidas nessas atividades.

\section{MATERIAL E MÉTODOS}

O levantamento de dados necessários ao desenvolvimento desta pesquisa ocorreu durante o mês de dezembro de 2009 em um viveiro de produção de mudas de eucalipto localizado no município de

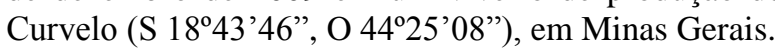

O viveiro avaliado produz mudas de Eucalyptus spp. numa média mensal de 250 mil plantas. A jornada de trabalho no viveiro é de 10 horas, de segunda a sexta-feira, iniciando às 07:00 h e finalizando às 17:00 h, com intervalo para o almoço de $1 \mathrm{~h}$, entre $11 \mathrm{e}$ 12:00 h.

Foram avaliados os setores de lavagem e desinfecção de tubetes e bandejas, embandejamento e enchimento de tubetes, preparo de substrato, jardim clonal, estaqueamento, casa de vegetação, casa de sombra e crescimento a céu aberto, seguindo metodologia sugerida por Alves (2004).

$\mathrm{Na}$ caracterização dos fatores do ambiente de trabalho - sensações térmicas (temperatura, umidade e velocidade do vento), ruído e luminosidade -, utilizou-se metodologia proposta por Marziale e Carvalho (1998), constituída por observação livre do trabalho e do ambiente, observação direta da unidade de trabalho e aferição de agentes físicos.

O clima no local de trabalho foi mensurado por meio de um termômetro digital de IBUTG (temperatura de bulbo seco e bulbo úmido e temperatura de globo), com medições horárias em ambiente com carga solar e sem carga solar, as quais foram comparadas com os limites estabelecidos pela Norma Regulamentadora (NR 15) da Lei $\mathrm{n}^{\circ}$ 6.514, de 23 de novembro de 1990. O Índice de Bulbo Úmido Termômetro de Globo (IBUTG) foi determinado pelas equações descritas a seguir, considerando-se os ambientes internos ou externos, sem carga solar, e ambientes externos com carga solar (VIEIRA, 2005): 
a) Ambientes internos ou externos sem carga solar:

IBUTG $=0,7$ tbn $+0,3$ tg

b) Ambientes externos com carga solar:

$$
\mathrm{IBUTG}=0,7 \mathrm{tbn}+0,1 \mathrm{tbs}+0,2 \mathrm{tg}
$$

Em que: tbn = temperatura de bulbo úmido natural $\left({ }^{\circ} \mathrm{C}\right)$;

$\operatorname{tg}=$ temperatura de globo $\left({ }^{\circ} \mathrm{C}\right)$;

tbs $=$ temperatura de bulbo seco $\left({ }^{\circ} \mathrm{C}\right)$.

A umidade e velocidade do vento foram mensuradas, respectivamente, com o uso dos aparelhos Instrutherm, modelos THDL 400 e TAD 500. Os níveis amostrados foram comparados aos recomendados na NR 17.

A luminosidade no local de trabalho foi medida utilizando-se um luxímetro digital da marca Instrutherm, modelo THDL 400, entendendo-se, como campo de trabalho, os locais onde eram realizadas as atividades de propagação de plantas. As leituras foram realizadas no decorrer da jornada de trabalho em intervalos de duas horas. $\mathrm{O}$ aparelho foi posicionado num plano horizontal onde as atividades eram realizadas, obtendo-se a leitura em lux.

O ruído foi mensurado por leitura instantânea com o uso do decibelímetro da marca Instrutherm, modelos THDL 400. O sensor do aparelho foi colocado na altura do ouvido do trabalhador, realizando as medições de acordo com a Norma Regulamentadora $n^{\circ} 15$ (NR 15), do Ministério do Trabalho e Emprego - Atividades e Operações Insalubres (VIEIRA, 2005). Os dados foram coletados em intervalos de 5 minutos durante toda a jornada de trabalho, sendo os valores de decibéis $(\mathrm{dB}(\mathrm{A}))$ lidos e anotados.

\section{RESULTADOS E DISCUSSÃO}

De acordo com as Normas Regulamentadoras do Ministério do Trabalho e Emprego (NR 15, em seu Anexo 3), o limite de tolerância para exposição ao calor não deve ultrapassar a 25,0;26,7 e $30^{\circ} \mathrm{C}$ para trabalhos classificados como leves, moderados e pesados, respectivamente. Segundo Alves et al. (2002), as atividades realizadas em um viveiro florestal podem ser consideradas moderadas, em regime de trabalho contínuo, sendo o máximo valor permitido do IBUTG igual a $26,7^{\circ} \mathrm{C}$.

Os valores de IBUTG médio apresentaram um comportamento crescente durante as primeiras horas da jornada de trabalho, havendo uma queda nos índices a partir das 13 horas, nos três ambientes avaliados (Figura 1).

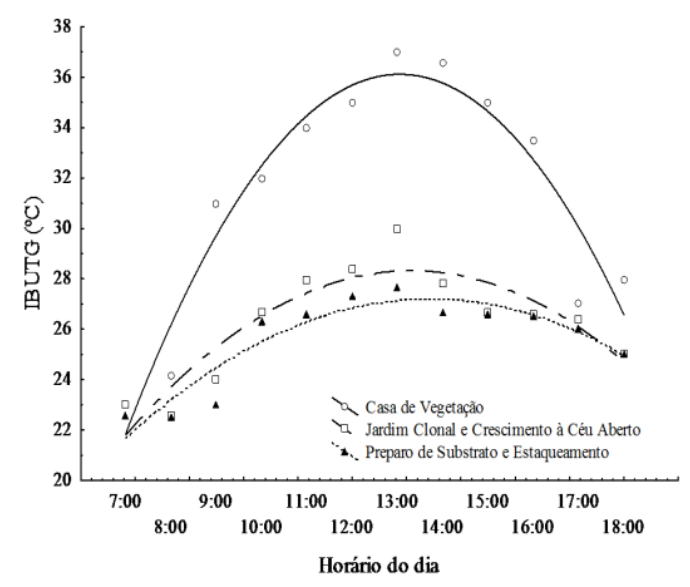

Figura 1. Variação do Índice de Bulbo Úmido - Termômetro de Globo (IBUTG) médio ao longo da jornada de trabalho na casa de vegetação, jardim clonal e crescimento a céu aberto, preparo de substrato e estaqueamento. Horário de verão de Brasília.

Figure 1. Variation of the Wet Bulb Index - Globe Thermometer (WBGT) average for the working day in house of vegetation, garden and clonal growth in the open, substrate preparation and cutting. Brasilia Summer time. 
Os períodos de 11 às 14 horas, 12 às 13 horas e 9 às 18 horas para as atividades dos setores de jardim clonal e crescimento a céu aberto, estaqueamento e preparo do substrato, e casa de vegetação, respectivamente, apresentaram condições climáticas adversas, ou seja, IBUTG superiores a $26,7{ }^{\circ} \mathrm{C}$. Segundo Alves et al. (2002), quando o organismo está desenvolvendo uma atividade fora da zona de conforto térmico, o trabalhador pode sentir-se desconfortável, perdendo a motivação para o trabalho, mesmo que este não seja qualificado; a velocidade de reação para o desenvolvimento das tarefas diminui; ocorre também perda de precisão, perda de continuidade e diminuição da vigilância, o que torna o ambiente impróprio para o trabalho mental e, ainda, aumenta a incidência de acidentes, principalmente aqueles sem maior gravidade.

Durante esses períodos há apenas intervalo para o almoço (11 às 12 horas) e o café da tarde (15 às 15:20 h), tornando-se necessário readequar o horário de trabalho em cada setor nesses períodos, devendo ser trabalhados 30 minutos e estabelecidos 30 minutos de descanso, conforme recomendação da NR 15, a fim de evitar que os trabalhadores desenvolvam suas atividades com sobrecarga térmica, reduzindo possíveis riscos de acidentes. Fiedler et al. (2007), avaliando as condições climáticas em atividades de poda de árvores na arborização urbana em Brasília, observaram que os valores máximos de IBUTG foram atingidos às 12 horas, mas, em função de esse horário crítico coincidir com o intervalo de almoço dos trabalhadores (11 às 13 horas), torna-se dispensável o estabelecimento de medida ergonômica em relação às condições climáticas.

A casa de vegetação, além de suas elevadas temperaturas (Figura 1), apresentou também valores de umidade relativa acima do recomendado pela NR 17 (Figura 2). Observa-se que nas primeiras horas da manhã a umidade desse setor é superior a 90\%, havendo uma queda contínua desse valor durante o transcorrer do dia, mas ocorrendo ligeiro aumento do índice no final da tarde.

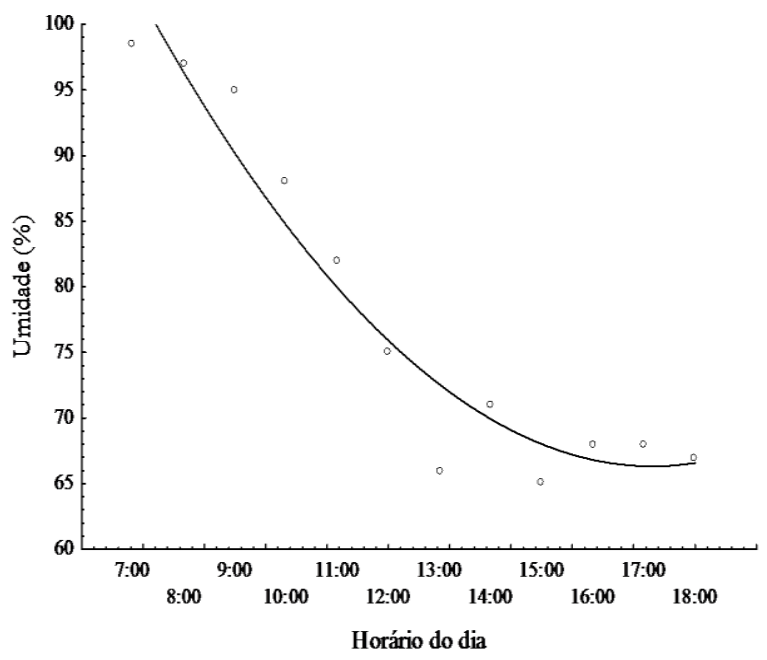

Figura 2. Variação da umidade relativa do ar média ao longo da jornada de trabalho na casa de vegetação. Horário de verão de Brasília.

Figure 2. Average variation of relative humidity for the working day in the greenhouse. Brasilia Summer time.

Ressalte-se que o objetivo desse ambiente é manter os altos valores de temperatura e umidade, visando à maximização do enraizamento das estacas. As atividades do setor são realizadas durante pequenos intervalos de tempo, mas de forma frequente, sendo necessária a constante hidratação dos funcionários, como medida preventiva.

A velocidade média diária do vento encontrada com medições horárias ao longo do turno de trabalho foi superior a mais de duas vezes o recomendado $\left(1,74 \mathrm{~m}^{-1}{ }^{-1}\right)$ (JACTO, 1999), observando-se que os horários entre 12 e 16 horas foram os mais críticos, apresentando picos máximos de até $3,3 \mathrm{~m} . \mathrm{s}^{-1}$. Essa informação é de suma importância para uma atividade de rotina em um viveiro florestal, que corresponde à aplicação de agrotóxicos (inseticidas, fungicidas e herbicidas). Essa atividade não é recomendada na 
presença de ventos com velocidades superiores a $10 \mathrm{~km} \cdot \mathrm{h}^{-1}\left(2,7 \mathrm{~m} \cdot \mathrm{s}^{-1}\right)$, para evitar os problemas de deriva na aplicação de defensivos agrícolas, que pode vir a prejudicar a saúde do operador e atingir alvos não pretendidos. Uma alternativa para controlar este problema pode ser o uso de quebra-vento, prática comum em viveiros florestais, uma vez que o vento excessivo pode prejudicar também a produção de mudas.

O comportamento da iluminância no setor de preparo de substrato e estaqueamento foi crescente até as 13 h, quando atingiu o máximo (601,13 lux), sofrendo declínio após esse horário (Figura 3). Em ambientes internos, para tarefas com requisitos visuais normais, segundo a norma NBR 5413 (ASSOCIAÇÃO BRASILEIRA DE NORMAS TÉCNICAS (ABNT), 1992), a iluminação geral para a área de trabalho deve estar entre 500 e 1000 lux.

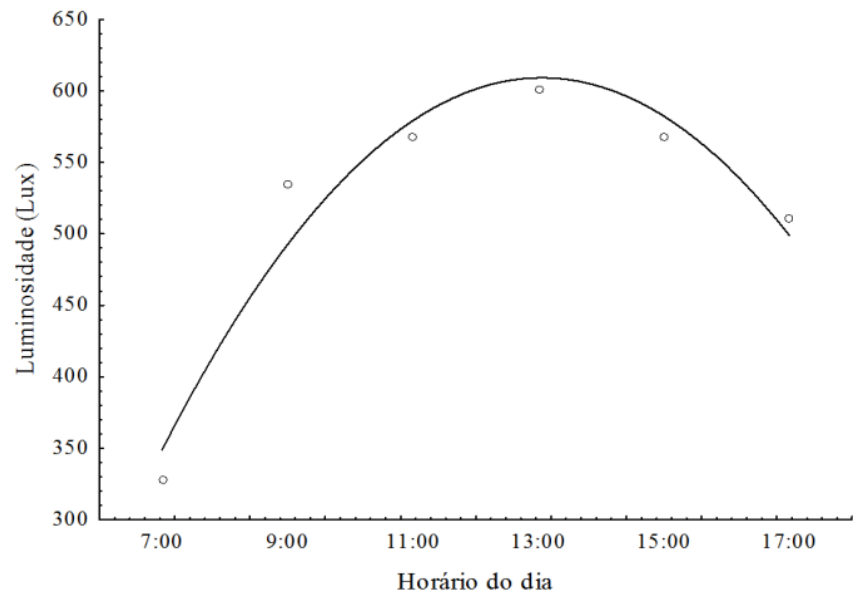

Figura 3. Variação da luminosidade média ao longo da jornada de trabalho no setor de preparo de substrato e estaqueamento. Horário de verão de Brasília.

Figure 3. Variation of the average brightness for the working day in the field of substrate preparation and staking. Brasilia Summer time.

Assim, apenas durante as primeiras horas do dia de trabalho ( 7 às $9 \mathrm{~h}$ ), a iluminância apresentouse como deficiente. Após esse horário, os valores encontrados apresentaram uma pequena variação, devido à existência de grandes aberturas laterais que favorecem a boa iluminação natural durante todo o dia nesse setor. Alves et al. (2002), avaliando o ambiente de trabalho de um viveiro florestal no Vale do Rio Doce, MG, comentaram também que a iluminância satisfatória do setor de estaqueamento da empresa durante o turno da manhã somente foi conseguida por abertura lateral no sentido leste, que contribui para o correto fornecimento de luminosidade para as atividades realizadas nesse ambiente de trabalho. Níveis de iluminação inadequados foram observados também por Lopes et al. (2004) em ambientes de trabalho de indústrias de processamento de madeira na região centro-sul do Paraná, onde os mesmos estavam insuficientes na maioria dos postos de trabalho, não atendendo aos valores estabelecidos pela NBR 5413 da ABNT.

Não foi possível mensurar a iluminância do ambiente externo do viveiro, correspondente aos setores de jardim clonal e crescimento a céu aberto, pois, durante todos os horários do dia, seus valores extrapolavam a escala do luxímetro utilizado ( 0 a 20.000 lux). Esse comportamento demonstra que os trabalhadores que realizam suas atividades nesses setores podem estar sujeitos a fadiga visual, pois, segundo Iida (2003), valores crescentes a partir de 1.000 lux podem proporcionar esse desconforto.

Quanto ao ruído, detectou-se nível superior ao recomendado pela NR 15 (85 dB(A)) apenas para o setor de preparo de substrato e estaqueamento na utilização de duas máquinas. Nos demais ambientes do viveiro, o nível de ruído ficou dentro dos limites estabelecidos pela norma, estando as doses diárias médias abaixo de $90 \%$ (Figura 4). O setor de preparo de substrato e estaqueamento apresentou maior percentual de ruído durante a jornada de trabalho (111\%) (Figura 4), sendo que a média diária do misturador de substrato (betoneira) foi de $90 \mathrm{~dB}(\mathrm{~A})$, e da máquina de enchimento de tubetes, $86 \mathrm{~dB}(\mathrm{~A})$.

O misturador de substrato é usado diariamente apenas duas vezes ao longo da jornada de trabalho. Já a máquina de enchimento de tubetes possui uma maior frequência de utilização, sendo 
acionada por poucos segundos a cada ciclo ao longo de todo o turno de trabalho. Apesar de não haver uma permanência prolongada do trabalhador responsável por operar o maquinário desse setor, ainda assim torna-se necessário o uso de protetor auricular, em decorrência do ruído estar acima de $85 \mathrm{~dB}(\mathrm{~A})$. Uma segunda alternativa seria a seleção de maquinários menos ruidosos entre os diversos modelos existentes no mercado, por ocasião de sua aquisição.

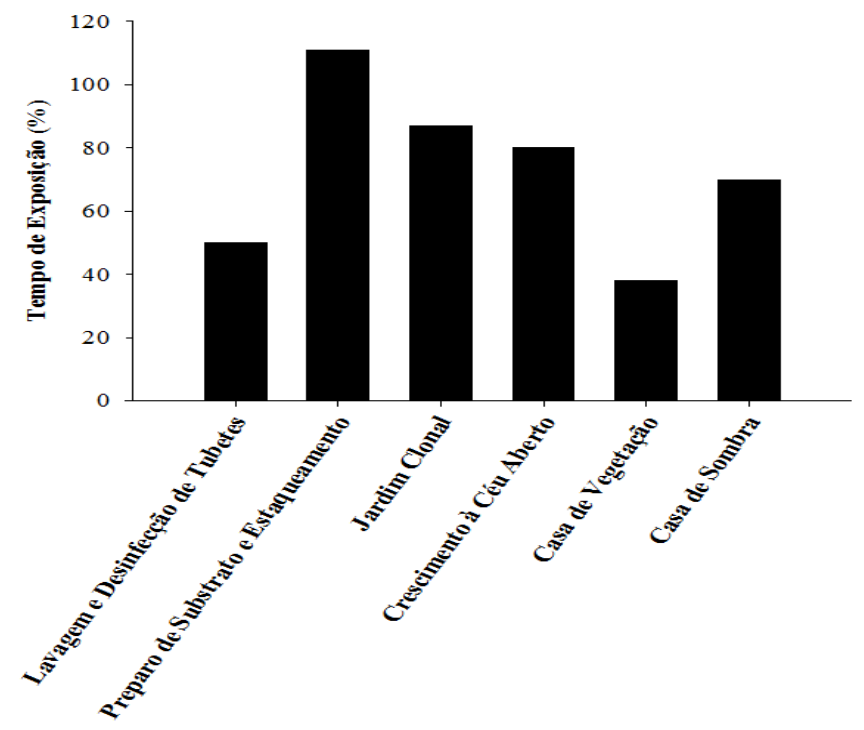

Figura 4. Dosagem de ruído durante a jornada de trabalho, em diferentes atividades de um viveiro florestal.

Figure 4. Strength of noise during the working day, in different activities of a forest nursery.

Os resultados obtidos por Alves et al. (2002) em análises de ruído das diferentes atividades realizadas na propagação de plantas corroboram os dados observados no presente trabalho. Os autores verificaram que na fase de lavagem de tubetes ocorreu o maior nível de ruído durante a jornada de trabalho, tendo sido a média diária de $86,5 \mathrm{~dB}(\mathrm{~A})$ e o maior pico, de $90 \mathrm{~dB}(\mathrm{~A})$. O ruído foi acima do limite recomendado pelas normas brasileiras também na desinfecção de tubetes, com média de 85,24 dB(A). Minetti et al. (2007), avaliando os níveis de ruído em máquinas de colheita florestal, observaram que em uma das empresas avaliadas as máquinas utilizadas (carregador florestal, fellerbuncher, traçador mecânico, skidder e mini-skidder) também apresentaram níveis de ruído superiores ao permitido pela legislação brasileira, sendo observado também que em todos os postos de trabalho os índices de temperatura estavam fora da zona de conforto térmico.

\section{CONCLUSÕES}

- As atividades realizadas no setor de casa de vegetação estão sujeitas a níveis de IBUTG e umidade superiores aos estabelecidos pelas NR's 15 e 17, respectivamente, ao longo de toda a jornada de trabalho.

- Os trabalhadores dos setores jardim clonal e crescimento a céu aberto estavam executando suas atividades ao longo de todo o dia de trabalho sob níveis de iluminação muito acima dos 1.000 lux, estando esses sujeitos a fadigas e desconfortos visuais.

- Os níveis de ruído registrados no setor de preparo de substrato e enchimento de tubetes foram superiores aos demais ambientes do viveiro, excedendo os $85 \mathrm{~dB}(\mathrm{~A})$ e consequentemente apresentando uma dosagem de ruído $11 \%$ superior ao recomendado, devido principalmente aos equipamentos existentes nesse local, tornando-se necessária a adoção de algumas medidas ergonômicas, com o objetivo de proteger os trabalhadores, como o uso de protetores auriculares e a manutenção preventiva dos equipamentos. 


\section{REFERÊNCIAS}

ASSOCIAÇÃO BRASILEIRA DE NORMAS TÉCNICAS (ABNT). NBR 5413 - Iluminância de interiores. Rio de Janeiro, 1992. 13 p.

ABRAHÃO, J. I.; PINHO, D. L. M. As transformações do trabalho e desafios teórico-metodológicos da Ergonomia. Estudos de Psicologia, n. 7, p. 45 - 52, 2002.

ALVES, J. U. Análise ergonômica da produção de mudas de eucalipto em viveiro, no vale do rio doce, MG. 2004. 112 p. Tese (Doutorado em Ciência Florestal) - Curso de Pós-Graduação em Ciência Florestal, Universidade Federal de Viçosa.

ALVES, J. U.; MINETTI, L. J.; SOUZA, A. P.; SILVA, K. R.; GOMES, J. M.; FIEDLER, N. C. Avaliação do ambiente de trabalho na propagação de Eucalyptus spp. Revista Brasileira de Engenharia Agrícola e Ambiental, v. 6, n. 3, p. 481 - 486, 2002.

FIEDLER, N. C.; VENTUROLI, F.; MINETTI, L. J. Análise de fatores ambientais em marcenarias no Distrito Federal. Revista Brasileira de Engenharia Agrícola e Ambiental, v. 10, n. 3, p. 679 - 685, 2006.

FIEDLER, N. C.; FERREIRA, A. H. S.; VENTUROLI, F.; MINETTI, L. J. Avaliação da carga de trabalho físico exigido em operadores de produção de mudas ornamentais no Distrito Federal - Estudo de caso. Revista Árvore, v. 31, n. 4, p. 703 - 708, 2007.

IIDA, I. Ergonomia: projeto e produção. São Paulo: Edgard Blucher, 2003. 465 p.

JACTO, S. A. Manual técnico sobre orientação de pulverização. Pombéia, Edição 10/99, 1999. 23 p.

LOPES, E. S.; ZANIORENZI, E.; COUTO, L. C.; MINETTI, L. J. Análise do ambiente de trabalho em indústrias de processamento de madeira na região centro-sul do Estado do Paraná. Scientia Florestalis, n. 66, p. 183 - 190, 2004.

MARZIALE, M. H. P.; CARVALHO, E. C. Condições ergonômicas do trabalho da equipe de enfermagem em unidade de internação de cardiologia. Revista Latino Americana de Enfermagem, v. 6, n. 1, p. 99 - 117, 1998.

MINETTI, L. J.; SILVA, E. P.; SOUZA, A. P.; SILVA, K. R. Avaliação dos níveis de ruído, luz e calor em máquinas de colheita florestal. Revista Brasileira de Engenharia Agrícola e Ambiental, v. 11, n. 6, p. $664-667,2007$.

SILVA, K. R.; SOUZA, A. P.; MINETTI, L. J. Avaliação do perfil de trabalhadores e das condições de trabalho em marcenarias do município de Viçosa-MG. Revista Árvore, v. 26, n. 6, p. 769 - 775, 2002.

VIEIRA, S. I. Manual de saúde e segurança do trabalho: segurança, higiene e medicina do trabalho. v. 3. São Paulo: LTr, 2005. 350 p. 
